\title{
Raman Spectroscopic Study of High-density Polyethylene during Tensile Deformation
}

\author{
Takumitsu Kida, Yusuke Hiejima* and Koh-hei Nitta \\ Department of Chemical and Materials Science, Kanazawa University, Kakuma Campus, Kanazawa 920-1192, Japan
}

\begin{abstract}
In situ Raman spectroscopy is applied to high-density polyethylene to elucidate the microscopic deformation mechanism during uniaxial stretching. The peak shifts of the $C-C$ stretching modes of the amorphous chains show remarkable red shifts in the elastic region, where as the red shift of the $\mathrm{C}-\mathrm{C}$ stretching vibration along the crystalline chain begins after the first yield point, suggesting that the stretching stress is concentrated on the amorphous chains before the first yield point. The $\mathrm{C}-\mathrm{C}$ stretching vibrations perpendicular to the crystalline chain, as well as the $\mathrm{CH}_{2}$ bending modes, show blue shifts in the yielding region, which is explained by the compression stress due to the densification of lamellar cluster units. After the yielding region, the orthorhombic crystalline structure is slightly expanded, and the stretching stress is applied on the crystalline and amorphous trans chains.
\end{abstract}

\section{Keywords}

Raman spectroscopy, Polyethylene, Peak shift, Load sharing, Tensile deformation

\section{Introduction}

Semi-crystalline polymers, such as high-density polyethylene (HDPE) have a variety of structures over a wide range of length scale. The supramolecular structures are spontaneously formed through complicated crystallization processes; the molecular chains are partially folded to form the lamellar crystals, followed by the radial growth of the lamellar crystals to form spherulites. It has been revealed that the hierarchical structures are responsible for the mechanical properties of semi-crystalline polymer solids such as strength and toughness [1].

It has been demonstrated that tensile deformation of semicrystalline polymer results in various structural changes [2]. Undrawn specimen has isotropic spherulitic structure which are collapsed during the yielding, and further drawing results in formation of fibrillar structures $[3,4]$. The mechanism of deformation has been investigated with various experimental methods [5-8]. For polymeric materials, the stress relaxation of specimen after unloaded from the mechanical testing machine results in appreciable structural changes [9]. Then, in situ spectroscopic observation during mechanical testing has a crucial role for investigation of microscopic mechanism of deformation.

Raman spectroscopic analyses have been applied for various materials, such as nanoparticles and polymer composites [10-16]. Rheo-optics which is methods of simultaneous measurements of spectroscopic observation and mechanical testing are powerful tools for investigation of deformation mechanism of polymeric materials. The rheo-optical apparatuses for the birefringence and the infrared (IR) absorption have been developed and applied to clarify the deformation mechanism of polyolefins $[17,18]$. Since the IR spectroscopy provides the molecular orientation of the amorphous chains as well as the crystalline chains, in situ IR spectroscopy has been applied for the uni- and biaxial deformation of films [19-21]. In radiation facilities, in situ small- and wide-angle X-ray scattering measurements have been conducted, and real-time monitoring of the crystalline orientation and the change of the crystallinity during elongation has been reported [22,23].

Since the vibrations of the skeletal C-C bonds are strongly Raman active, the microscopic environments of the polymer chains are probed by the Raman spectroscopy. It has been demonstrated that the spectral shift of Raman bands are interpreted as the microscopic stress applied on the polymer chains [24,25]. Raman spectroscopy has been utilized for determination of the morphology and the crystalline modulus of semi-crystalline polymers of undrawn and highly-drawn specimens under tension [7,24,26-28]. In situ observation of the load sharing on the polymer chains by monitoring the peak shift is quite limited, and the discussion on the microscopic structural changes relies only on a few Raman bands such as the $\mathrm{C}-\mathrm{C}$ stretching and the $\mathrm{CH}_{2}$ rocking modes $[9,26,27,29]$.

In this study, we have conducted the rheo-Raman spectroscopy for HDPE under uniaxial tensile test. The spectral shifts of several Raman bands assigned to the crystalline and amorphous phases

*Corresponding author: Y. Hiejima, Department of Chemical and Materials Science, Kanazawa University, Kakuma Campus, Kanazawa 920-1192, Japan, E-mail: hiejima@se.kanazawa-u.ac.jp

Received: December 31, 2015: Accepted: January 22, 2016: Published: January 25, 2016

Copyright: (c) 2016 Kida T, et al. This is an open-access article distributed under the terms of the Creative Commons Attribution License, which permits unrestricted use, distribution, and reproduction in any medium, provided the original author and source are credited. 

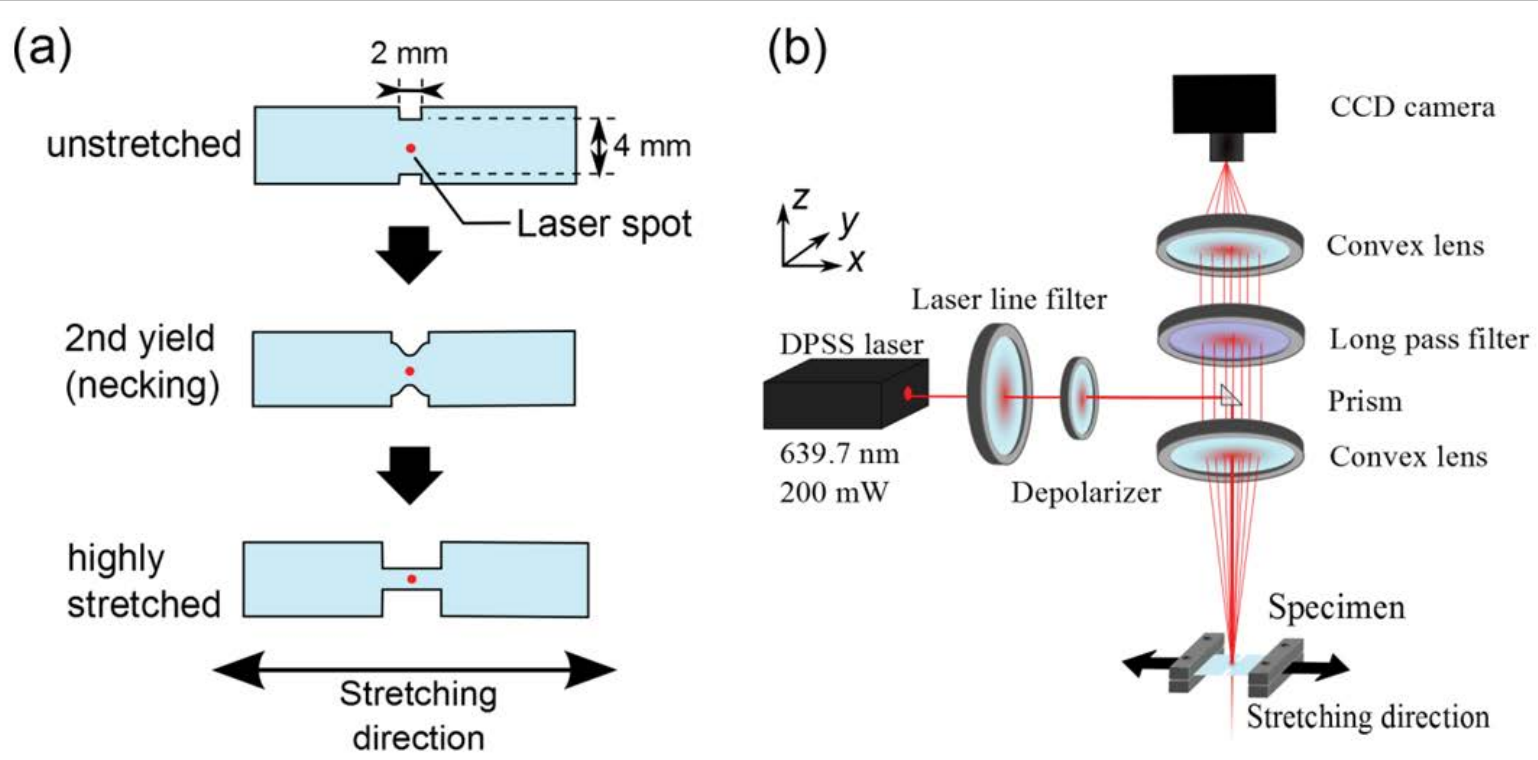

Figure 1: Schematic illustrations of (a) insitu Raman spectroscopic system with the tensile tester and (b) HDPE specimens during tensile testing. The red spot on each specimen represents the laser spot.

are obtained simultaneously. By combining with the peak shifts in the highly-oriented HDPE specimen under tension, microscopic deformation mechanism of HDPE is discussed.

\section{Experimental}

Ziegler-Natta-catalyzed HDPE pellets $\left(M_{\mathrm{w}}=10 \times 10^{4}, M_{\mathrm{w}} / M_{\mathrm{n}}\right.$ $=5.9)$ were used. The pellets were melted in a laboratory hot press for $5 \mathrm{~min}$ at $483 \mathrm{~K}$ and $10 \mathrm{MPa}$ and then quenched in iced water, to prepare a sheet with a thickness of about $1 \mathrm{~mm}$. The sample sheets were annealed in an oven at $353 \mathrm{~K}$ for $5 \mathrm{~h}$. The density of the sample was determined by the Archimedes method and its volumetric crystallinity was determined from the density, where the densities of the amorphous and the crystalline regions were assumed to be $\rho_{a}=$ $855 \mathrm{~kg} / \mathrm{m}^{3}$ and $\rho_{c}=1000 \mathrm{~kg} / \mathrm{m}^{3}$, respectively [30]. The test specimens were cut out of the sample sheet with a notch-shaped die $(2 \mathrm{~mm}$ gauge length, $4 \mathrm{~mm}$ width) shown in Figure 1(a). Highly-oriented specimens were prepared as follows. The HDPE specimen was drawn at $373 \mathrm{~K}$ up to the strain of 2 , and held for $10 \mathrm{~min}$, then left at room temperature for 1 day.

The apparatus for the rheo-Raman spectroscopy is shown schematically in Figure 1(b). A custom-made tensile tester with a double-drawing mechanism was installed in the Raman spectroscopic apparatus. Laser light from a DPSS laser (LASOS, Jena, Germany, $637.9 \mathrm{~nm}$ in wavelength, $200 \mathrm{~mW}$ in laser power) was monochromated with a laser line filter, and irradiated into the notched portion of the specimen, with a spot size of $1 \mathrm{~mm}$ in diameter. Since the two grips of the tensile tester move toward the opposite directions at the same rate, the center of the specimen was irradiated during the entire tensile testing. It is also noteworthy that the necking of the specimen is always initiated at the center of the notch-shaped specimen. The elongation speed was set to $1 \mathrm{~mm} / \mathrm{min}$, and the stretching temperature was $20^{\circ} \mathrm{C}$. The scattered light was collected with a pair of convex lenses, where the excitation light was removed with a Raman long-pass filter. A chargecoupled device camera equipped with a monochromator (PIXIS 100 and SpectraPro 2300i, Princeton Instruments, Trenton, USA, NJ) was used as the detector. The Raman spectra were accumulated 10 times with an exposure time of $500 \mathrm{~ms}$ (Figure 2).

The peak shift is defined as the deviation of the Raman shift from that of the undrawn specimen:

$$
\Delta v=v-v_{0}
$$

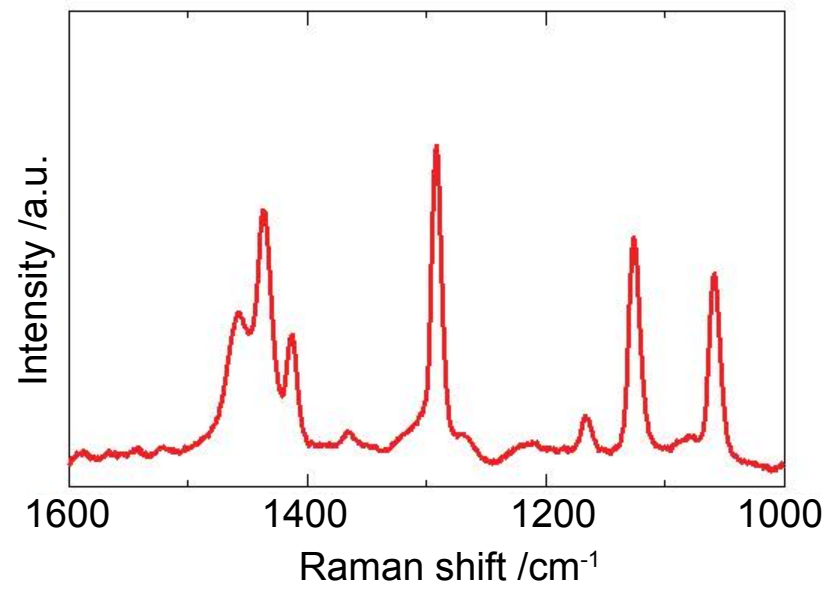

Figure 2: Raman spectrum of undrawn HDPE specimen.

where the subscript 0 denotes the undrawn specimen. It has been observed that the IR and Raman bands show substantial shifts during deformation [24,25,31].The anti-symmetric $\left(1063 \mathrm{~cm}^{-1}\right)$ and symmetric $\left(1130 \mathrm{~cm}^{-1}\right) \mathrm{C}-\mathrm{C}$ stretching modes are the vibrations of the skeletal chains parallel and perpendicular to the chain axis, respectively. Then, the peak shifts of the $\mathrm{C}-\mathrm{C}$ stretching modes have been used to detect the load sharing on the polymer chains $[7,26]$. Although the Raman band at $1080 \mathrm{~cm}^{-1}$ assigned to the $\mathrm{C}-\mathrm{C}$ stretching mode of the amorphous chains only shows broad and weak peak as seen in Figure 3(a), sufficiently high S/N ratio of the present system enable us to fit the Raman band successfully.

Three distinctive peaks around $1400 \mathrm{~cm}^{-1}$ are assigned to the $\mathrm{CH}_{2}$ bending modes. Since the $1418 \mathrm{~cm}^{-1}$ band assigned to the $\mathrm{CH}_{2}$ bending in the orthorhombic crystal is classified into the space group of $A_{g}$, this band is used to estimate the orientation of the crystalline chains [32,33]. The $1418 \mathrm{~cm}^{-1}$ band is also useful for estimation of the crystallinity of polyethylene [34-36]. The $1440 \mathrm{~cm}^{-1}$ and $1460 \mathrm{~cm}^{-1}$ bands are assigned to the $\mathrm{CH}_{2}$ bending modes of the amorphous trans chains and the melt-like amorphous chains, respectively [35,37]. It is proposed that the former chains exist in the intermediate phase between the crystalline and amorphous regions with in the threephase model $[38,39]$. 

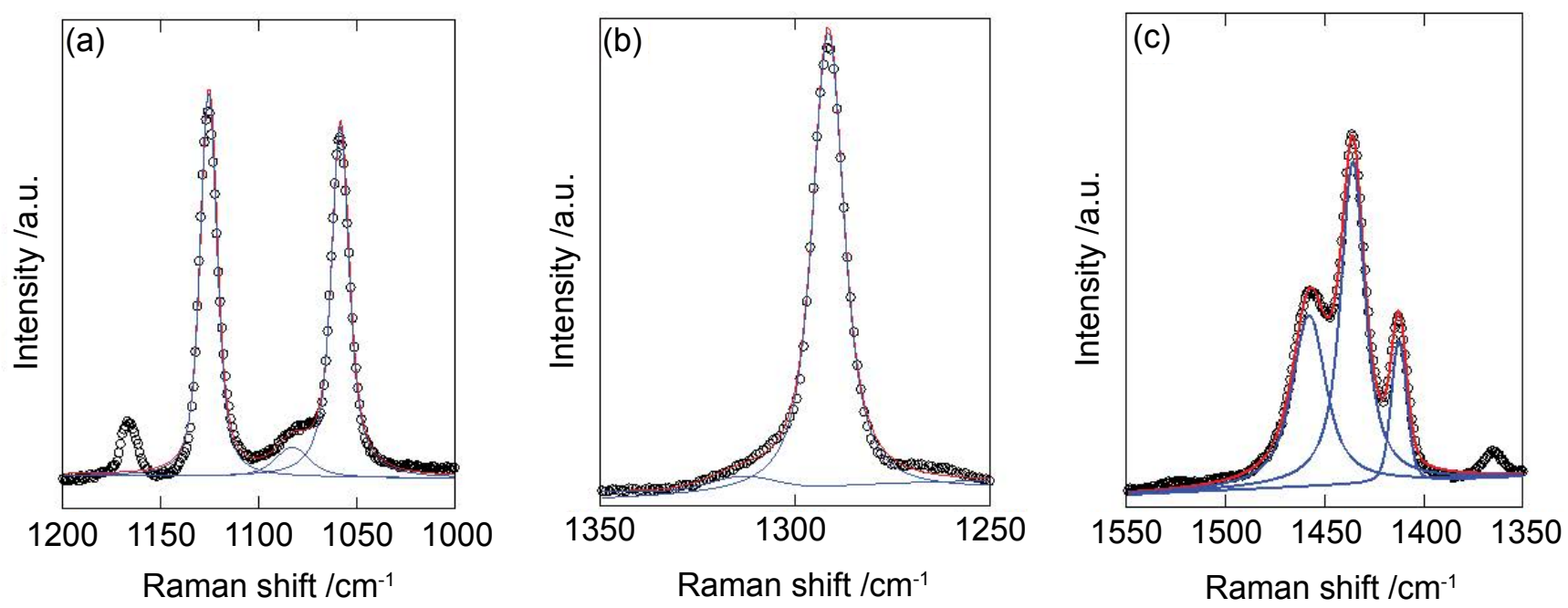

Figure 3: Raman spectra (circles) of undrawn specimen. The red line represents the fitting with a sum of Voigt functions (blue lines)

Table 1: Vibrational phase and Raman tensor form of the Raman spectrum of polyethylene [32,33,42,43].

\begin{tabular}{|l|l|l|l|}
\hline Raman shift $/ \mathrm{cm}^{-1}$ & Mode & Phase & Raman tensor \\
\hline 1063 & $v_{\text {as }}(\mathrm{C}-\mathrm{C})$ & Trans chain & $\mathrm{B}_{2 g}+\mathrm{B}_{3 g}$ \\
\hline 1080 & $v(\mathrm{C}-\mathrm{C})$ & Amorphous & - \\
\hline 1130 & $v_{\mathrm{s}}(\mathrm{C}-\mathrm{C})$ & Trans chain & $\mathrm{A}_{\mathrm{g}}+\mathrm{B}_{1 \mathrm{~g}}$ \\
\hline 1298 & $v_{\mathrm{t}}(\mathrm{C}-\mathrm{C})$ & Crystalline & $\mathrm{B}_{2 \mathrm{~g}}+\mathrm{B}_{3 \mathrm{~g}}$ \\
\hline 1313 & $v_{\mathrm{t}}(\mathrm{C}-\mathrm{C})$ & Amorphous & - \\
\hline 1418 & $\delta\left(\mathrm{CH}_{2}\right)$ & Crystalline & \\
\hline 1440 & $\omega\left(\mathrm{CH}_{2}\right)$ & (orthorhombic) & $\mathrm{A}_{\mathrm{g}}$ \\
\hline 1460 & $\delta\left(\mathrm{CH}_{2}\right)$ & $\begin{array}{l}\text { Amorphous trans } \\
\text { (intermediate) }\end{array}$ & $\mathrm{A}_{\mathrm{g}}+\mathrm{B}_{1 \mathrm{~g}}$ \\
\hline & $\delta\left(\mathrm{CH}_{2}\right)$ & Amorphous & $\mathrm{A}_{\mathrm{g}}+\mathrm{B}_{1 \mathrm{~g}}$ \\
\hline
\end{tabular}

$v$ : stretching; $v_{a s}$ : anti-symmetric stretching; $v_{s}$ : symmetric stretching;

$v_{t}$ : twisting; $\delta$ : bending; $\omega$ : wagging

The Raman bands at $1298 \mathrm{~cm}^{-1}$ and $1313 \mathrm{~cm}^{-1}$ are assigned to the $\mathrm{CH}_{2}$ twisting modes of the crystalline and amorphous chains, respectively. These bands are commonly used as the internal standards to estimate the crystallinity [34,40], and molecular orientation [32,41].

\section{Results and discussion}

\section{Characterization and Raman spectra of unstretched specimen}

The density and the volumetric crystallinity were determined to be $951 \mathrm{~kg} / \mathrm{m}^{3}$ and $66 \%$, respectively. The Raman spectrum of the undrawn HDPE specimen was shown in Figure 2 and the assignments for the Raman bands was listed in Table $1[32,33,42,43]$. The Raman bands for the crystalline chain $\left(1063,1130,1298\right.$ and $\left.1418 \mathrm{~cm}^{-1}\right)$ and the amorphous chain $\left(1080,1440\right.$ and $\left.1460 \mathrm{~cm}^{-1}\right)$ were used in the following analysis. As shown in Figure 3, each Raman band was successfully fitted with a sum of Voigt functions using a nonlinear Levenberg-Marquardt method.

\section{Stress-strain behavior of HDPE}

In Figure 4, a typical stress-strain curve and the shapes of specimen during uniaxial stretching are shown for HDPE. Before the first yield point (denoted as A) at which the stress shows a maximum, the specimen is deformed homogeneously. Beyond the first yield point, the stress decreases and shear bands appear in the notched portion of the specimen. Around the second yield point (B), a concave construction is developed in the central portion of (a)

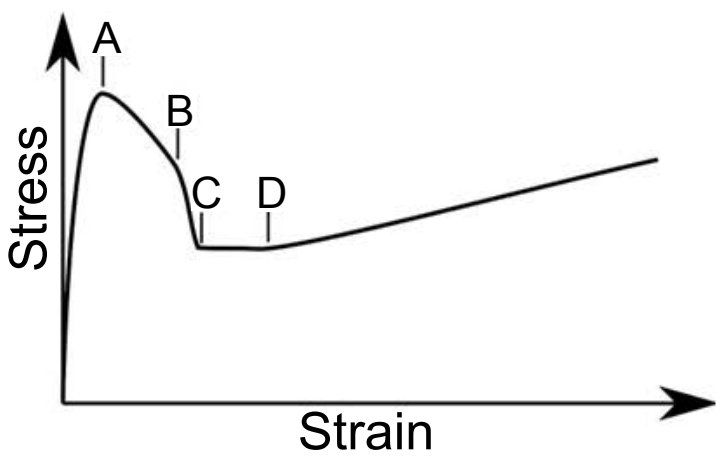

(b)

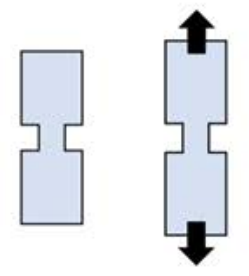

Unstretched A

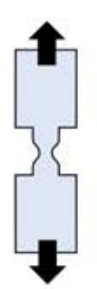

B
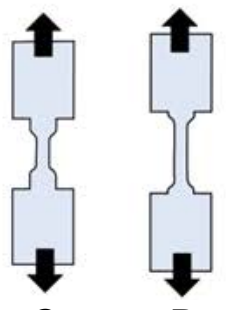

Figure 4: Schematic illustrations of (a) typical stress-strain curve of HDPE and (b) macroscopic deformation of HDPE specimen. A: first yield point, $\mathrm{B}$ : second yield point, C: initiation of neck propagation, D: onset of strain hardening.

the specimen, and an inhomogeneous deformation called necking initiates between $\mathrm{B}$ and $\mathrm{C}$. After the yielding region, the necked portion propagates towards the both ends of the specimen (D). After the neck-propagation is completed, the increase of the stress resumes in the strain-hardening region.

\section{Raman spectral shifts of highly-oriented HDPE under tension}

Figure 5 shows the stress dependences of the peak shifts of Raman bands assigned to the crystalline and amorphous chains of the highlyoriented HDPE specimen. Because the crystalline and amorphous chains in highly-oriented specimens are oriented toward the stretching direction, it is suggested that these peak shifts are induced by the tensile stress applied along the crystalline and amorphous chains. 

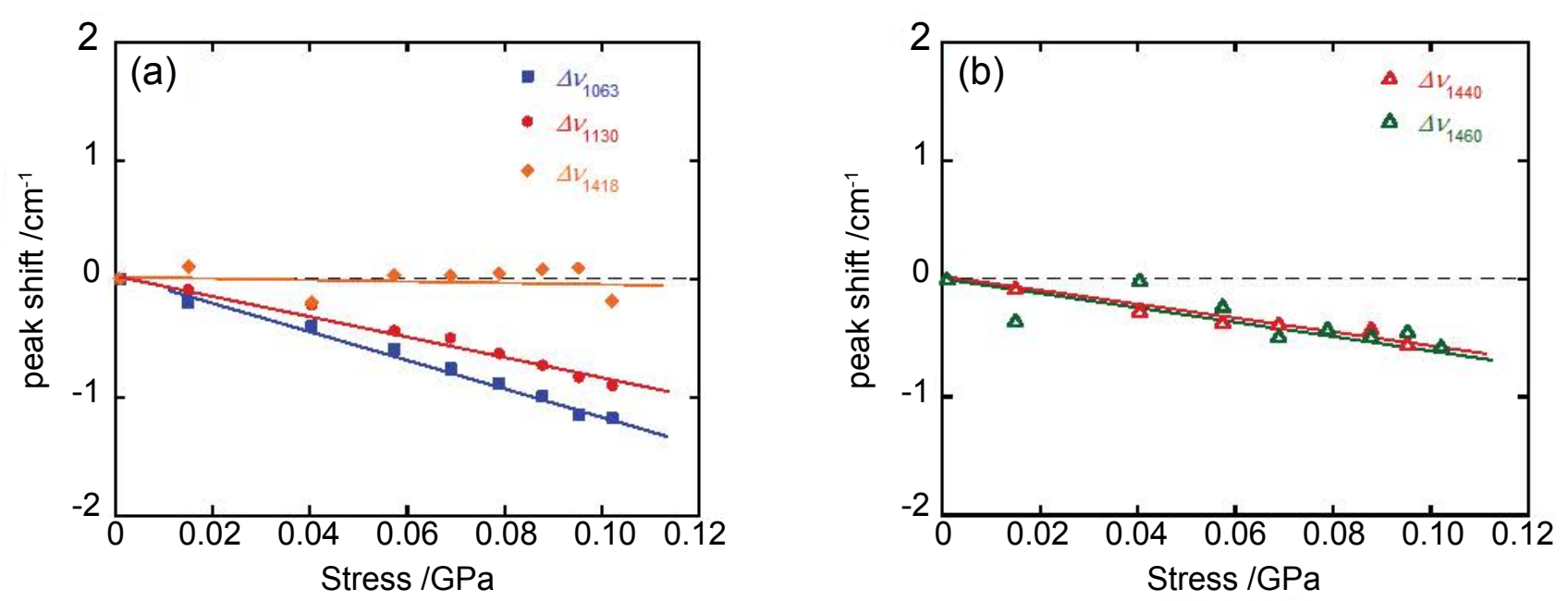

Figure 5: Stress dependences of peak shifts of highly-oriented HDPE specimen under tension for Raman bands assigned to (a) crystalline and (b) amorphous chains.
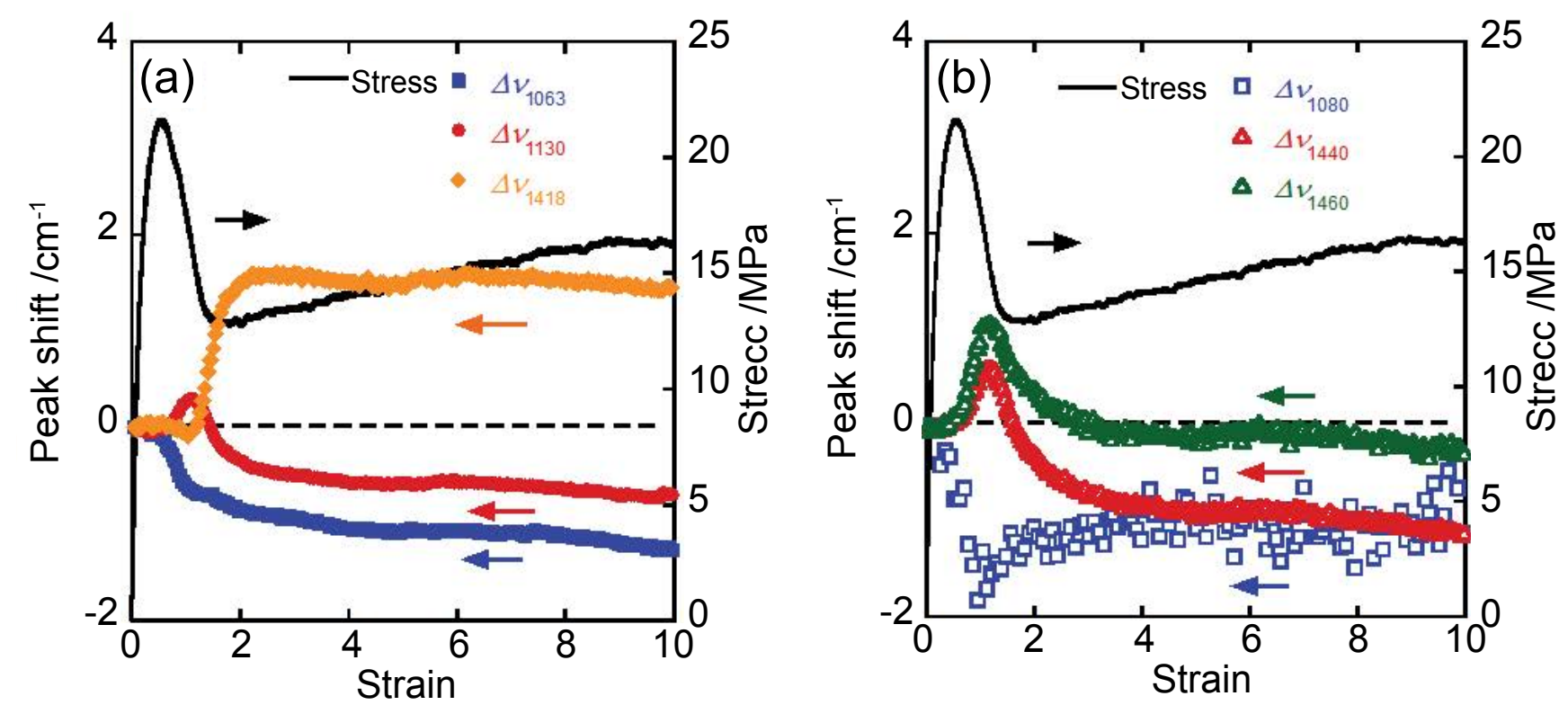

Figure 6: Strain dependences of peak shifts of Raman bands assigned to (a) crystalline and (b) amorphous chains under uniaxial stretching.

The two Raman bands at 1063 and $1130 \mathrm{~cm}^{-1}$ assigned to the crystalline chains show obvious red shifts under stretching, and the shift factors $\alpha$ (slopes of Figure 5) are determined to be $-11.3 \mathrm{~cm}^{-1} /$ $\mathrm{MPa}$ and $-7.7 \mathrm{~cm}^{-1} / \mathrm{MPa}$, respectively. These values are in good agreement with those reported previously [7,24]. On the contrary, the Raman bands assigned to the $\mathrm{C}-\mathrm{C}$ twisting and the $\mathrm{CH}_{2}$ bending modes show substantially smaller shifts factors $\left(\alpha_{1298}=-2.2 \mathrm{~cm}^{-1} /\right.$ $\left.\mathrm{MPa}, \alpha_{1440}=-5.5 \mathrm{~cm}^{-1} / \mathrm{MPa}, \alpha_{1460}=-5.2 \mathrm{~cm}^{-1} / \mathrm{MPa}\right)$ than the $\mathrm{C}-\mathrm{C}$ stretching modes, indicating that the torsional motions of the main chain and the librational motions of $\mathrm{CH}_{2}$ groups are less affected by the stretching stress. The difference of the sensitivity to the stretching of a single chain has also been predicted from the lattice dynamical calculations [25,31]; their calculation has demonstrated that the applied stress is concentrated on the $\mathrm{C}-\mathrm{C}$ stretching and the $\mathrm{C}-\mathrm{C}-\mathrm{C}$ bending modes, and that the vibrations of the pendant $\mathrm{H}$ atoms are not affected. The blue shifts of the $\mathrm{C}-\mathrm{C}$ stretching and twisting modes as well as the $\mathrm{CH}_{2}$ bending modes have been observed in ultra-highmolecular-weight polyethylene under hydrostatic pressure, which have been interpreted as the hindrance of the vibrational motions by the compression due to dense packing under high pressures [44].
The shift factor of the $\mathrm{CH}_{2}$ bending mode of the orthorhombic crystalline chains is found to be practically zero $\left(\alpha_{1418}=-0.06 \mathrm{~cm}^{-1} /\right.$ $\mathrm{MPa}$ ). From the WAXS experiments [44], it is found that the 1418 $\mathrm{cm}^{-1}$ band strongly depends on the cross section of the unit cell of the orthorhombic crystal, where blue shift is observed for smaller cross section. Since the $1418 \mathrm{~cm}^{-1}$ band also shows red shift under hydrostatic pressure [44], it is plausible that the competition of these two effects cancel out the pressure dependence of $\alpha_{1418}$.

\section{Raman spectral shifts of the HDPE during tensile deformation}

The strain dependences of peak shifts of various Raman bands of HDPE during tensile test are shown in Figure 6 along with the stress-strain curve of HDPE. As shown in Figure 4, the deformation of specimen proceeds from the elastic region (up to the first yield point) to the yielding region (up to the neck-initiation), followed by the strain-hardening region (after neck-propagation). It is noteworthy that the necking region is quite narrow for the notchshaped specimens. In accordance with these deformation stages, each Raman band show characteristic shifts as discussed in the following subsections, except for the 1298 and $1313 \mathrm{~cm}^{-1}$ bands which are 
insensitive to deformation

\section{C-C stretching modes $\left(1100 \mathrm{~cm}^{-1}\right.$ range)}

In the elastic region, the peak shifts of the 1063 and $1130 \mathrm{~cm}^{-1}$ bands assigned to the $\mathrm{C}-\mathrm{C}$ stretching modes of the crystalline chains remain zero, suggesting no stress is applied on the crystalline chains. On the contrary, the $1080 \mathrm{~cm}^{-1}$ band assigned to the C-C stretching modes of the amorphous chains shows drastic red shift, and the shift linearly increases with the strain. Then, it is suggested that the stretching stress is concentrated only on the amorphous chains [45-47]. After the first yield point, $\Delta v_{1063}$ begins to decrease with the strain, suggesting the increase of the stretching stress applied along the crystalline chains. On the other hand, $\Delta v_{1130}$ shows a sharp rise and has a maximum around the second yield point, which has been interpreted with the compression due to the densification of the lamellar cluster units $[48,49]$. After the second yield point, $\Delta v_{1130}$ drops and $\Delta v_{1063}$ shows a narrow plateau, suggesting that the microscopic stress imposed on the crystalline chains is released. The red shift of the $1080 \mathrm{~cm}^{-1}$ band also slightly decreases, suggesting that the plastic deformation such as the reorientation of the lamellar cluster units $[26,48,49]$ leads to decrease of the overall stress level in the amorphous phase as well as the crystalline phase. In the strain-hardening region, all of the Raman bands at 1063, 1080 and $1130 \mathrm{~cm}^{-1}$ show red shifts weakly dependent on the strain, suggesting that almost constant stretching stress is applied on both of the crystalline and amorphous chains after the plastic deformation is completed.

\section{$\mathrm{CH}_{2}$ bending modes $\left(1400 \mathrm{~cm}^{-1}\right.$ range)}

In the elastic region, the peak shifts $\Delta v_{1418}, \Delta v_{1440}$ and $\Delta v_{1460}$ for the $\mathrm{CH}_{2}$ bending modes remain zero, as shown in Figure 6. After the first yield point, $\Delta v_{1440}$ and $\Delta v_{1460}$ for the amorphous chains sharply increases with the strain, and show a maximum around the second yield point, suggesting the hindrance of the $\mathrm{CH}_{2}$ bending motions. Around the first yield point, $\Delta v_{1418}$ begins to deviate from zero and has a shallow minimum around the second yield point, which is interpreted as the narrowing of the crystalline lattice. These peculiar behaviors in the yielding region are explained by the compression stress caused by the densification of lamellar cluster units [48-50]. Since the $1460 \mathrm{~cm}^{-1}$ band assigned to the amorphous chains shows larger blue shifts than the $1440 \mathrm{~cm}^{-1}$ band assigned to the trans chains in the intermediate phase, the compression stress seems to be mainly imposed on the amorphous phase. After the second yield point, $\Delta v_{1418}$ shows a steep rise, suggesting the expansion of the orthorhombic crystal cell. In the strain-hardening region, $\Delta v_{1460}$ is practically zero, suggesting no stress is applied on the amorphous phase. In spite of the relatively small shift factor, the $1440 \mathrm{~cm}^{-1}$ band shows large red shift, implying the amorphous trans chains such as tie molecules $[43,44]$ are extremely stretched.

\section{Conclusion}

In situ Raman spectroscopy was applied to HDPE under uniaxial stretching, and the spectral shifts of several Raman bands assigned to the crystalline and amorphous chains were obtained during the elongation process. By combining these peak shifts which provided information on the changes in the microscopic environment of each mode, deformation mechanism was discussed. In the elastic region, only the C-C stretching mode of the amorphous chains showed red shift, suggesting the stretching stress was loaded on the amorphous chains. After the first yield point, the stretching stress along the crystalline chains increased with the strain. Between the first and second yields, the compression stress due to the densification of the lamellar cluster units was imposed both on the crystalline and amorphous phases. After the second yield point, where the lamellar cluster units began to orient toward the stretching direction, the compressive stress was released, accompanied by the slight expansion of the orthorhombic crystal. In the strain-hardening region, the stretching stress along the crystalline and amorphous trans chains increased, implying the tie molecules are extremely stretched.

\section{Acknowledgment}

This work is financially supported by JSPS KAKENHI (Grant Number 26410221).

\section{References}

1. Ward IM, Sweeney J (2013) Mechanical Properties of Solid Polymers (3rd ed.). Wiley.

2. Oleinik EF (2003) Plasticity of Semicrystalline Flexible-Chain Polymers at the Microscopic and Mesoscopic Level. Polym Sci Ser C 45: 17-117.

3. Peterlin A (1971) Molecular Model of Drawing Polyethylene and Polypropylene. J Mater Sci 6: 490-508.

4. Peterlin A (1987) Drawing and extrusion of semi-crystalline polymers. Colloid Polym Sci 265: 357-382.

5. Glenz W, Peterlin A (1971) Infrared studies of drawn polyethylene. II Orientation behavior of highly drawn linear and ethyl-branched polyethylene. J Polym Sci Part A-2 9: 1191-1217.

6. Butler M, Donald A, Bras W, Mant GR, Derbyshire GE, et al. (1995) A realtime simultaneous small-and wide-angle X-ray scattering study of in-situ deformation of isotropic polyethylene. Macromolecules 28: 6383-6393.

7. Tashiro K, Wu G, Kobayashi M (1988) Morphological effect on the Raman frequency shift induced by tensile stress applied to crystalline polyoxymethylene and polyethylene: spectroscopic support for the idea of an inhomogeneous stress distribution in polymer material. Polymer 29: 1768-1778.

8. Olf HG, Peterlin A (1974) Laser-Raman Study of the Longitudinal Acoustic Mode in Polyethylene. J Polym Sci Polym Phys Ed 12: 359-384.

9. Hiejima Y, Kida T, Nitta K-H (2015) Rheo-Raman Spectroscopic Study of Uniaxial Plastic Deformation Behavior in High-Density Polyethylene Solids. In: Wythers MC, Advances in Materials Science Research. Nova.

10. Ritter U, Scharff P, Dmytrenko OP, Kulish NP, Prylutskyy YI, et al. (2010) Strength Improvement of iPP/MWCNT Nanocomposites. Polym Compos 31: 179-184

11. Perets YS, Matzui LY, Vovchenko LL, Prylutskyy YI, Scharff P, et al. (2014) The effect of boron nitride on electrical conductivity of nanocarbon-polymer composites. J Mater Sci 49: 2098-2105.

12. Dmytrenko OP, Kulish NP, Prylutskyy YI, Shpilevskiy EM, Belyi NM, et al. (2004) Raman spectra and structure of thin $\mathrm{Cu}-\mathrm{C} 60$ films. Thin Solid Films 459: 254-257.

13. Ritter U, Scharff P, Dmytrenko OP, Kulish NP, Prylutskyy YI, et al. (2007) Radiation damage and Raman vibrational modes of single-walled carbon nanotubes. Chem Phys Lett 447: 252-256.

14. Popa CL, Ciobanu CS, Voicu G, Vasile E, Chifiriuc MC, et al. (2015) Influence of Thermal Treatment on the Antimicrobial Activity of Silver-Doped Biological Apatite. Nanoscale Res Lett 10: 502

15. Ciobanu CS, Iconaru SL, Chifiriuc MC, Costescu A, Le Coustumer P, et al. (2013) Synthesis and antimicrobial activity of silver-doped hydroxyapatite nanoparticles. Biomed Res Int 2013: 916218.

16. Lazarenko A, Vovchenko L, Matsui D, Prylutskyy Y, Matzuy L, et al. (2008) Electrical and Thermal Conductivity of Polymer-Nanocarbon Composites. Mol Cryst Liq Cryst 497: 397-407.

17. Onogi S, Tanaka A, Ishikawa Y, Igarashi T (1975) Rheo-optical Studies on Drawn Polyethylene Films. Polym J 7: 467-480

18. Tanaka A, Saihara Y, Onogi S (1980) Relationship between Elastic Recovery and Macroscopic- and Microscopic- Structures of Hydrogenated Polybutadiene Films. Polym J 12: 483-494.

19. Song Y, Nitta K-H, Nemoto N (2003) Deformation Mechanisms of Polymer Thin Films by Simultaneous Kinetic Measurement of Microscopic Infrared Dichroism and Macroscopic Stress. 2. Molecular Orientation during Necking Process of Isotactic Polypropylene. Macromolecules 36: 1955-1961.

20. Li H, Zhou W, Ji Y, Li L, Li Z-M, et al. (2013) Spatial distribution of crystal orientation in neck propagation: An in-situ microscopic infrared imaging study on polyethylene. Polymer 54: 972-979.

21. Nitta K-H, Sawada T, Yoshida S, Kawamura T (2015) Three dimensional molecular orientation of isotactic polypropylene films under biaxial deformation at higher temperatures. Polymer 74: 30-37.

22. Jiang Z, Tang Y, Men Y, Enderle H-F, Lilge D, et al. (2007) Structural Evolution of Tensile-Deformed High-Density Polyethylene during Annealing: 
Scanning Synchrotron Small-Angle X-ray Scattering Study. Macromolecules 40: 7263-7269

23. Tang Y, Jiang Z, Men Y, An L, Enderle HF, et al. (2007) Uniaxial deformation of overstretched polyethylene: In-situ synchrotron small angle $X$-ray scattering study. Polymer 48: 5125-5132.

24. Wool RP, Bretzlaff RS, Li BY, Wang CH, Boyd RH (1986) Infrared and Raman Spectroscopy of Stressed Polyethylene. J Polym Sci Part B Polym Physicsl 24: 1039-1066.

25. Tashiro K, Kobayashi M, Gang W (1990) Quasiharmonic treatment of infrared and raman vibrational frequency shifts induced by tensile deformation of polymer chains. J Polym Sci Part B Polym Phys 28: 2527-2553.

26. Kida T, Oku T, Hiejima Y, Nitta K-H (2015) Deformation mechanism of highdensity polyethylene probed by in situ Raman spectroscopy. Polymer 58 : 88-95.

27. Kida T, Hiejima Y, Nitta K-H (2015) Rheo-optical Raman study of microscopic deformation in high-density polyethylene under hot drawing. Polym Test 44 30-36.

28. Rodríguez-Cabello JC, Merino JC, Jawhari T, Pastor JM (1996) Rheo-optical Raman Study of Chain Deformation in Uniaxially Stretched Bulk Isotactic Polypropylene. J Raman Spectrosc 27: 463-467.

29. Martin J, Poncot M, Hiver JM, Bourson P, Dahoun A (2013) Real time Raman spectroscopy measurements to study the uniaxial tension of isotactic polypropylene: a global overview of microstructural deformation mechanisms. J Raman Spectrosc 44: 776-784.

30. Brundrup J, Immergut EH, Grulke EA, Abe A, Bloch DR (1999) Polymer Handbook. 4th ed. New York: Wiley.

31. Tashiro K, Minami S, Wu G, Kobayashi M (1992) Quasiharmonic treatment of infrared and raman vibrational frequency shifts induced by tensile deformation of polymer chains. II. Application to the polyoxymethylene and isotactic polypropylene single chains and the three-dimensional orthorhombic polyethylene crystal. J Polym Sci Part B Polym Phys 30: 1143-1155.

32. Gall M, Hendra P, Peacock O, Cudby MEA, Willis HA (1972) The laser-Raman spectrum of polyethylene: The assignment of the spectrum to fundamental modes of vibration. Spectrochim Acta Part A Mol Spectrosc 28A: 1485-1496.

33. Gall M, Hendra P, Peacock C, Cudby M, Willis H (1972) Laser-Raman spectrum of polyethylene: Part 1 . Structure and analysis of the polymer. Polymer 13: 104-108.

34. Rull F, Prieto AC, Casado JM, Sobron F, Edwards HGM (1993) Estimation of Crystallinity in Polyethylene by Raman Spectroscopy. J Raman Spectrosc 24: $545-550$

35. Strobl G, Hagedorn W (1978) Raman spectroscopic method for determining the crystallinity of polyethylene. J Polym Sci Polym Phys 16: 1181-1193.

36. Migler KB, Kotula AP, Hight Walker AR (2015) Trans -Rich Structures in Early Stage Crystallization of Polyethylene. Macromolecules 48: 4555-4561.
37. Luu DV, Cambon L, Lapeyre C (1980) Caracterisation des Phases dans le Polyethylene par Effet Raman. J Raman Spectrosc 9: 172-175.

38. Mutter R, Stille W, Strobl G (1993) Transition regions and surface melting in partially crystalline polyethylene: A raman spectroscopic study. J Polym Sci Part B Polym Phys 31: 99-105.

39. Martin B, Jawhari T, Pastor JM, Merino JC (1996) Micro-Raman study of the longitudinal acoustic modes (LAM) evolution along the transition front in uniaxially stretched HDPE. Colloid Polym Sci 274: 285-289.

40. Lin W, Cossar M, Dang V, Teh J (2007) The application of Raman spectroscopy to three-phase characterization of polyethylene crystallinity. Polym Test 26: 814-821.

41. Bower DI (1972) Investigation of molecular orientation distributions by polarized raman scattering and polarized fluorescence. J Polym Sci Polym Phys Ed 10: 2135-2153.

42. Bailey RT, Hyde AJ, Kim JJ, McLeish J (1977) Raman studies on oriented, high modulus, polyethylene. Spectrochim Acta Part A Mol Spectrosc 33A: 1053-1058.

43. Schachtschneider J, Snyder R (1963) Vibrational analysis of the n-paraffinsII: Normal co-ordinate calculations. Spectrochim Acta 19: 117-168.

44. Zhao Y, Wang J, Cui Q, Yang M, Shen J (1990) High-pressure Raman studies of ultra-high-molecular-weight polyethylene. Polymer 31: 1425-1428.

45. Nitta K-H (1999) A molecular theory of stress-strain relationship of spherulitic materials. Comput Theor Polym Sci 9: 19-26.

46. Nitta K-H, Takayanagi M (2003) Direct observation of the deformation of isolated huge spherulites in isotactic polypropylene. J Mater Sci 38: 4889-4894.

47. Xiong B, Lame O, Chenal J-M, Rochas C, Seguela R, et al. (2014) In-situ SAXS study of the mesoscale deformation of polyethylene in the pre-yield strain domain: Influence of microstructure and temperature. Polymer 55: 1223-1227.

48. Kuriyagawa M, Nitta K-H (2011) Structural explanation on natural draw ratio of metallocene-catalyzed high density polyethylene. Polymer 52: 3469-3477.

49. Nitta K-H, Kuriyagawa M (2011) Application of catastrophe theory to neck initiation of metallocene-catalyzed high-density polyethylene. Polym J 44: 245-251.

50. Prasad K, Grubb DT (1989) Direct observation of taut tie molecules in highstrength polyethylene fibers by Raman spectroscopy. J Polym Sci Part B Polym Phys 27: 381-403. 